\title{
Vocal Corollary Discharge Communicates Call Duration to Vertebrate Auditory System
}

\author{
Boris P. Chagnaud ${ }^{1,2}$ and Andrew H. Bass ${ }^{2}$ \\ ${ }^{1}$ Department of Biology II, Ludwig-Maximilians-University Munich, 82152 Munich, Germany, and ${ }^{2}$ Department of Neurobiology and Behavior, Cornell \\ University, Ithaca, New York 14853
}

Corollary discharge is essential to an animal's ability to filter self-generated from external stimuli. This includes acoustic communication, although direct demonstration of a corollary discharge that both conveys a vocal motor signal and informs the auditory system about the physical attributes of a self-generated vocalization has remained elusive for vertebrates. Here, we show the underlying synaptic activity of a neuronal vocal corollary discharge pathway in the hindbrain of a highly vocal species of fish. Neurons carrying the vocal corollary discharge are specifically adapted for the transmission of duration information, a predominant acoustic cue. The results reveal that vertebrates, like some insects, have a robust corollary discharge conveying call duration. Along with evidence for the influence of vocal duration on auditory encoding in mammals, these new findings suggest that linking vocal motor and corollary discharge pathways with pattern generating, call duration neurons is a shared network character across the animal kingdom.

\section{Introduction}

Stimulation of the auditory system during self-vocalization is a phenomenon known as auditory reafference (Poulet and Hedwig, 2007). Studies in crickets show that a corollary discharge originating from the song pattern generator informs the auditory system about syllable generation, resulting in reduced responses to reafference during song (Poulet and Hedwig, 2006, 2007). Although the influence of self-vocalization on audition is apparent in vertebrates as diverse as fish and mammals, including humans (Suga and Schlegel, 1972; Cheung et al., 2005; Weeg et al., 2005; Eliades and Wang, 2008; Ford et al., 2010), the source and information conveyed within the brain by a vocal corollary discharge (VCD) remain to be identified for any vertebrate.

Many fish species, including midshipman (Porichthys notatus), produce highly stereotyped vocalizations in social contexts (e.g., a repetitive series or "train" of agonistic calls commonly referred to as "grunts") (Fig. 1A, top left) (Bass and McKibben, 2003). Vocalization results from the simultaneous contraction of paired swim bladder muscles in response to synchronous input from vocal nerves homologous to hypoglossal roots that innervate avian syringeal muscles (Bass et al., 2008). Vocal nerve activity directly determines both the rate at which individual calls, such as grunts, are produced (Fig. $1 A$, top), as well as the sound

\footnotetext{
Received July 25, 2013; revised Sept. 22, 2013; accepted Oct. 19, 2013.

Author contributions: B.P.C. and A.H.B. designed research; B.P.C. performed research; B.P.C. and A.H.B. analyzed data; B.P.C. and A.H.B. wrote the paper.

This work was supported by National Institutes of Health Grant DC00092. We thank Robert Baker, Roberto Banchi, Bruce Carlson, Ni Feng, Kevin Rohmann, Hans Straka, and Robert Wyttenbach for comments on an earlier version.

The authors declare no competing financial interests.

Correspondence should be addressed to either of the following: Dr. Boris P. Chagnaud, Department of Biology II, Ludwig-Maximilians-University Munich, 82152 Munich, Germany, E-mail: b.chagnaud@gmail.com; or Dr. Andre H. Bass, Department of Neurobiology and Behavior, Cornell University, Ithaca, NY 14853, E-mail: ahb3@cornell.edu. DOI:10.1523/JNEUROSCI.3140-13.2013

Copyright $\odot 2013$ the authors $\quad 0270-6474 / 13 / 3318775-06 \$ 15.00 / 0$
}

pulse repetition rate (PRR; equal to fundamental frequency in fish) and total duration of each call (Fig. 1A, bottom) (Bass and Baker, 1990; Rubow and Bass, 2009). Consequently, we refer to each burst of patterned vocal nerve activity in the absence of vocal muscle contraction as a fictive call that in this case is a grunt. Each nerve spike arises from the synchronous output of a hindbrain vocal motor nucleus (Fig. $1 B$ ) that matches the activity of single motoneurons (Fig. 1C) (Bass and Baker, 1990; Chagnaud et al., 2012). The patterning of motoneuron activity, and hence fictive and natural grunts, is determined by separate hindbrain populations coding for duration, PRR/frequency, and amplitude within a vocal central pattern generator (CPG) that includes the vocal motor nucleus (Fig. 1B) (Chagnaud et al., 2011, 2012).

One potential target for a VCD are hindbrain neurons common to all vertebrates that provide efferent input to auditory hair cells in the inner ear (Roberts and Meredith, 1992; Weeg et al., 2005; Köppl, 2011). In midshipman, these auditory efferent (AE) neurons also receive direct input from the vocal CPG (vocal prepacemaker nucleus [VPP], Fig. 1B) (Chagnaud et al., 2011). Here, intracellular recordings show that AE neurons generate a VCD specifically adapted for the coding of call duration, a major acoustic attribute for midshipman fish and sonic vertebrates in general (Bass and McKibben, 2003; Bradbury and Vehrencamp, 2011). Somewhat surprisingly, these new findings together with comparable studies in crickets, and more indirect evidence of vocal-audio information transfer in mammals, indicate that linking vocal motor and corollary discharge pathways with patterngenerating, duration-coding neurons is a character broadly shared across the animal kingdom.

\section{Materials and Methods}

Animals. Twenty-five midshipman fish (12.7-18.4 cm, standard length) were used in this study. Midshipman have two male reproductive morphs. Only nest-building type I males were used as they are more readily available and more vocally active than females and the sneak- 
spawning type II males. Animals were hand collected in northern California, shipped to Cornell University, and housed in an environmentally controlled room with a light:dark cycle of $14: 10 \mathrm{~h}$ at $16^{\circ} \mathrm{C}$. Fish were fed on a weekly diet of goldfish. All procedures followed previously described methods (Chagnaud et al., 2011) and were approved by the Cornell University Institutional Animal Care and Use Committee.

Surgery. In brief, before surgery, fish were anesthetized by immersion in $0.025 \%$ ethyl $p$-amino benzoate (Sigma) in artificial seawater. A solution of bupivacaine $(0.25 \%)$ and epinephrine $(0.01 \mathrm{~g} / \mathrm{ml})$ was injected into the cranial muscle every $4 \mathrm{~h}$ for additional anesthesia. The cranium was entered dorsally to expose the brain and the ventral occipital nerve roots that innervate sonic muscles. Animals were given intramuscular injections of pancuronium bromide $(0.5 \mathrm{mg} / \mathrm{kg}$ body weight; Astra Pharmaceutical Products) for immobilization and were transferred to the experimental tank. A tube inserted into the fish's mouth provided recirculated chilled seawater across the gills. The experimental tank rested on a vibration isolation table (Technical Manufacturing). Water temperature in the experimental tank was $16 \pm 2^{\circ} \mathrm{C}$.

Vocal motor stimulation and nerve recordings. Burst-like vocal nerve activity (i.e., fictive grunts; Fig. 1) was monitored with an extracellular electrode (75- $\mu$ m-diameter, Tefloncoated silver wire with an exposed ball tip; $125-200 \mu \mathrm{m}$ in diameter) placed on one occipital, vocal nerve root (Fig. 1). Both sides of the brain fire in phase (Bass and Baker, 1990). Nerve recordings were amplified 1000 times and bandpass filtered from $300 \mathrm{~Hz}$ to $5 \mathrm{kHz}$ with a differential AC amplifier (model 1700, A-M Systems). Fictive grunts occurred spontaneously or were evoked by either electrical stimulation (Bass and Baker, 1990) or by microinjection of $0.1 \mathrm{M}$ glutamate into vocal midbrain areas (Weeg et al., 2005). Electrical stimulation was delivered using insulated tungsten electrodes ( $5 \mathrm{M} \Omega$ impedance; A-M Systems) lowered into vocal midbrain areas (Bass and Baker, 1990; Goodson and Bass, 2002). Current pulses (amplitude range, 3-10 $\mu \mathrm{A}$ ) were delivered via a constant cur-

rent source (model 305-B, World Precision Instruments). A stimulus generator (A310 accupulser, World Precision Instruments) was used to generate a TTL pulse train with interpulse intervals ranging from 100 to $300 \mathrm{~Hz}$ and a total pulse number of $1-10$ pulses per train (standard settings were 5 pulses at $200 \mathrm{~Hz}$ ). Intervals between pulse trains ranged from 0.7 to $1.0 \mathrm{~s}$. A custom-built microinjection system was used for pressure injection of glutamate (1-3, $50 \mathrm{~ms}$ duration pulses at a pressure of $20-25 \mathrm{psi}$ ) via glass microelectrodes ( $1 \mathrm{~mm}$ diameter, broken tips of $10-15 \mu \mathrm{m})$.

Intracellular neuron recordings. Intracellular electrodes $(1.5 \mathrm{~mm}$ diameter) were pulled on a horizontal puller (P97, Sutter Instruments) and filled with 5\% neurobiotin (Vector Laboratories) in $0.5 \mathrm{M}$ potassium acetate (resistance: $35-60 \mathrm{M} \Omega$ ). Neuronal signals were amplified 100 times (Biomedical Engineering) and digitized at a rate of $20 \mathrm{kHz}$ (Digidata 1322A, Molecular Devices) using the software pCLAMP 9 (Molecular Devices). An external clock (Biomedical Engineering) sending TTL pulses was used to synchronize stimulus delivery and data acquisition. While searching for neurons, a current
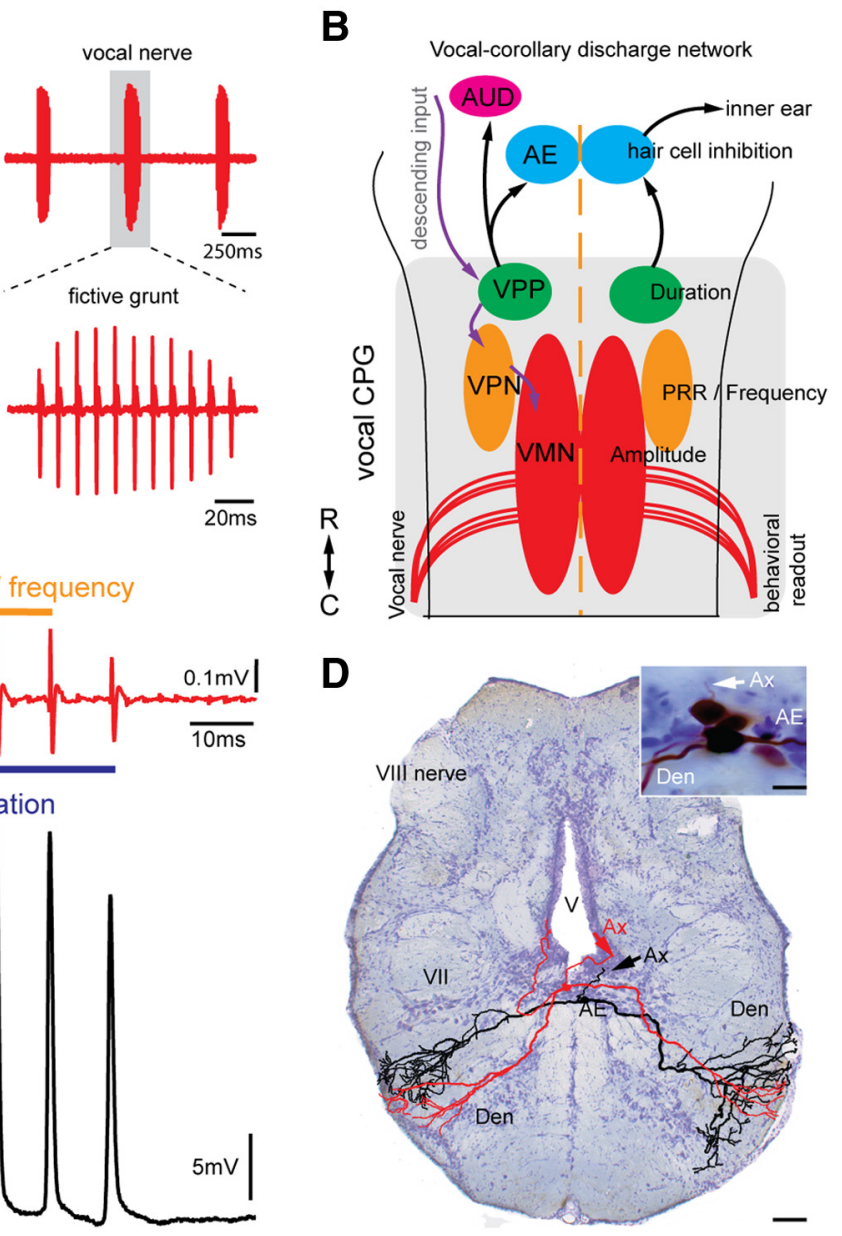

Figure 1. VCD to efferent neurons. $\boldsymbol{A}$, Left panels, Underwater hydrophone recording of natural call series showing an agonistic "grunt train" (top, black), and individual grunt (bottom, black). Right panels, Vocal nerve motor volley, directly predicts temporal 列

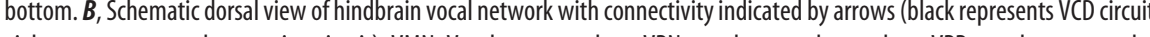

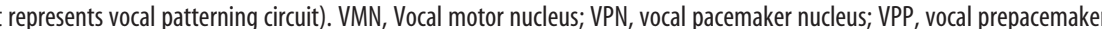

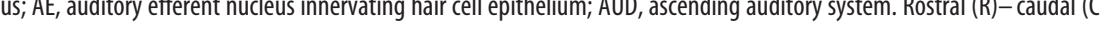
a pulse), highlighting that single motoneuron activity predicts duration and PRR of fictive call and, in turn, section of hindbrain showing two intracellular, neurobiotin-filled and reconstructed AE neurons (color-coded for clarity) with characteristic bilateral dendritic arbor (Den) that overlaps ascending vocal brainstem pathway (Bass et al., 1994). Inset, Photomicrograph of labeled neurons. Ax, Axon; V, ventricle; VII, facial motor nucleus.

step applied to the recording electrode was used to monitor electrode resistance. A piece of aluminum foil shielded the recording electrodes from the midbrain stimulation electrode and significantly decreased electrical artifact. AE neurons were hyperpolarized below action potential threshold to suppress spiking.

Intracellular neurobiotin labeling. Positive current (4-10 nA) with a duty cycle of $50 \%$ at $2-4 \mathrm{~Hz}$ was passed through the intracellular recording electrode for 3-30 min to inject neurobiotin into the neurons from which we obtained recordings. Fish survived from 4 to $6 \mathrm{~h}$ after neurobiotin injection to allow for dye transfer into neuronal processes and were then deeply anesthetized ( $0.025 \%$ benzocaine) and perfused with cold, teleost Ringer's solution with $10 \mathrm{U} / \mathrm{ml}$ of heparin (Elkins-Sinn), followed by a solution of $3.5 \%$ paraformaldehyde and $0.5 \%$ glutaraldehyde in phosphate buffer. Brains were postfixed (2-12 h) and transferred to $0.1 \mathrm{M}$ phosphate buffer, $\mathrm{pH} 7.2$, for storage. Brains were embedded in gelatin and sectioned (120 $\mu \mathrm{m}$ thick) on a microtome. Sections were reacted with an $\mathrm{ABC}$ kit (Vector Laboratories), mounted on gelatincoated slides, and counterstained with cresyl violet. 
A

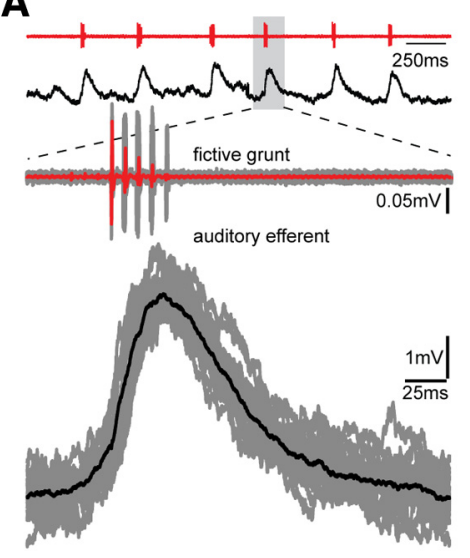

B

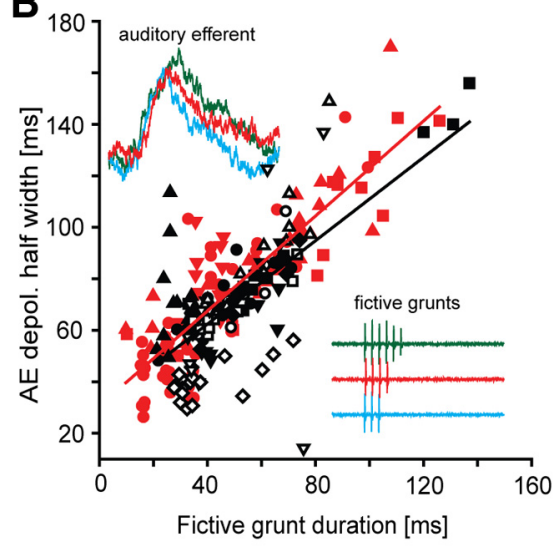

Figure 2. Hindbrain efferent neuron activity correlates with call duration. $\boldsymbol{A}$, Top two traces, Vocal nerve records for fictive grunt train (red) and corresponding intracellular AE neuron recording (black). Bottom traces, Expanded responses for nerve (gray, single trace highlighted in red) and intracellular (gray, single trace highlighted in black) records for individual grunt aligned to onset of grunt activity. $\boldsymbol{B}$, Relationship between grunt duration and half-width duration of AE depolarization responses during electrically evoked (black, $n=10$ neurons) and spontaneous or glutamate-evoked grunts (red, $n=5$ ); different symbols represent different neurons, with multiple symbols representing different trials. Lines indicate respective linear regressions. Inset, Color-coded fictive grunts (lower right inset) of various durations and corresponding intracellular response of single AE neuron (top left inset).

Neurons were reconstructed using a camera lucida attachment to a microscope (Leitz Orthoplan) at a magnification of $400 \times$. Drawings were scanned and further processed with the software Photoshop 7.0 (Adobe). Photographs of sections were taken using a microscope (Nikon Eclipse ES800) with attached digital camera (SPOT Flex, Diagnostics Instruments) and were postprocessed with the software Photoshop 7.0 (Adobe).

Neurophysiological analysis. Neuronal data were analyzed using the software IGOR pro 6 (Wavemetrics), the free software package neuromatic (www.neuromatic.thinkrandom.com), and self-written scripts (B.P.C.). Fictive grunts and intracellularly recorded AE neuron activity were recorded and analyzed using raster plots and peri-event time averages. Fictive grunts were analyzed by measuring the time between the first (the last stimulus artifact for electrical-evoked responses) and the last spike in each grunt-like burst of the motor volley. Duration of AE depolarizations was measured between the first (the last electrical stimulus artifact) and the last time a threshold was crossed (threshold level defined as half the amplitude of the maximum depolarization for AE recordings). Onset, calculated only for spontaneous or glutamate-evoked grunts, was the time point where the threshold was first crossed. To check for repetitive input after the PRR of fictive grunts, event-triggered averages were generated, using the first spike of a fictive grunt as an event trigger.

\section{Results}

In vivo intracellular recordings were made in 119 putative $\mathrm{AE}$ neurons while simultaneously recording fictive grunts from the vocal nerve. Intracellular neurobiotin fills confirmed AE location in a subset of these neurons $(n=9)$ (Fig. $1 D)$; their morphology, including axonal trajectory, matched previous descriptions (Highstein and Baker, 1986; Bass et al., 1994). In 66 of these neurons, we found neuronal activity directly correlated with the occurrence of grunts. To investigate underlying cellular mechanisms leading to the VCD, AE neurons were hyperpolarized below resting membrane potential and action potential threshold to suppress spiking. The activity of AE neurons during fictive grunts was characterized by a single depolarizing potential concurrent with each fictive grunt (Fig. $2 A$, grunt train, top red trace; AE neuron response, top black trace). Depolarization onset was either just before (Fig. 2A, two bottom sets of traces that are expansion of boxed area in top traces) or during each fictive grunt but, on average, occurred soon after the first nerve spike of each fictive grunt $(7.99 \pm 11.62 \mathrm{~ms} ; n=11$ neurons generating spontaneous or glutamateevoked grunts). The duration of AE depolarizations was highly correlated with grunt duration, regardless of whether grunts were electrical or spontaneous/glutamate induced (Fig. 2B, electrical, black symbols: linear regression $y=0.80^{\star} x+$ $29.9, R^{2}=0.47$; spontaneous, red symbols: linear regression $y=0.92^{\star} x+30,5$, $\left.R^{2}=0.75\right)$. This robust relationship was consistent with direct input to AE from duration-coding neurons of the vocal CPG (VPP, Fig. 1B) (Chagnaud et al., 2011). AE membrane potentials returned toward the hyperpolarized resting membrane potential in the silent intervals between repetitive grunts (Fig. $2 A$, top two traces).

We next wanted to know whether AE neurons carry PRR information (i.e., the repetition rate of sound pulses represented in the fictive preparation by individual nerve spikes) (Fig. 1C). Six of 66 AE neurons exhibited oscillatory activity superimposed on the depolarizing potential. Response averaging revealed small oscillations just preceding fictive grunt nerve spikes; their magnitude diminished greatly soon after the first few spikes (Fig. $3 A$, black trace is average of responses, in gray, aligned to nerve spikes as indicated by vertical lines). Despite this weak encoding of PRR, the depolarizing potentials in these six AE neurons exhibited a strong duration signal (Fig. $3 A$, inset; linear regression $y=0.8^{\star} x+$ 25.4, $R^{2}=0.88$ ), like other AE neurons (Fig. $2 B$ ).

Consistent with direct input from the vocally active midbrain periaqueductal gray to AE neurons (Kittelberger and Bass, 2013), electrical stimulation in the periaqueductal gray region led to synaptic responses in AE neurons (Fig. 3B). This allowed us to investigate synaptic integration via a direct manipulation of $\mathrm{AE}$ input at different stimulation frequencies. AE neurons showed a summation of EPSPs at frequencies $<60 \mathrm{~Hz}$ (Fig. 3B) (i.e., well below the range of natural PRR/fundamental frequency; $\geq 100$ $\mathrm{Hz}$ ) (Bass and McKibben, 2003). Hence, the summation of synaptic input by AE neurons makes them effective for carrying call duration, but not PRR/fundamental frequency.

\section{Discussion}

An individual's motor behavior leads to sensory reafference (i.e., self-stimulation). To prevent or diminish responses to reafference, motor systems inform sensory systems about imminent or ongoing activity via corollary discharges (Crapse and Sommer, 2008). Here, we identified, for the first time, the synaptic activity underlying vocal-audio information transmission in a vertebrate by a corollary discharge (VCD) circuit. We further show that the VCD predominantly informs the auditory system about call duration (Fig. 4).

\section{Duration versus PRR/frequency transmission}

Midshipman vocalizations, like those of other vertebrates, exhibit a multiharmonic frequency spectrum encoded by the auditory system (Bass and McKibben, 2003; Rohmann et al., 2013). Vocal CPG neurons (Fig. $1 B$ ), however, only determine PRR and fundamental frequency (Chagnaud et al., 2011). Because harmonics, 
A

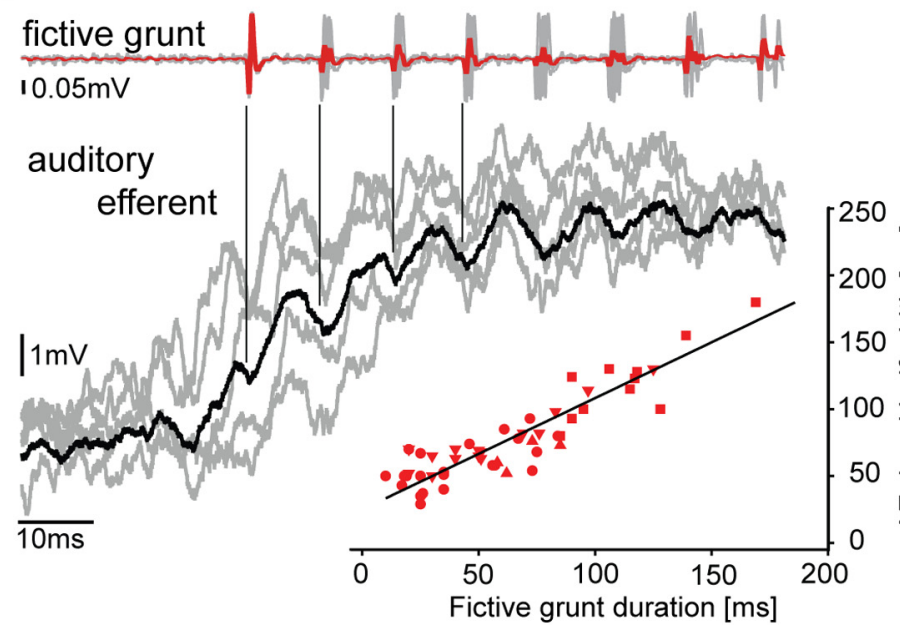

B

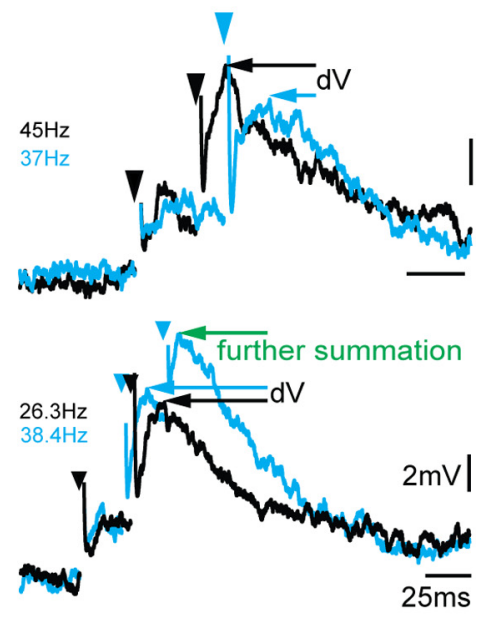

Figure 3. Auditory efferent neurons are not adapted to transmit PRR/frequency information. $\boldsymbol{A}$, Event-triggered average of single AE neuron activity (black trace is average of responses, shown in gray) aligned to first nerve spike and corresponding fictive grunt reveals time-locked, low-amplitude oscillations (indicated by vertical lines) in AE neuron relative to individual nerve spikes (repetition rate of spikes determines natural call) (Chagnaud et al., 2012). Lower right inset, Strong relationship between duration of fictive grunt and duration of AE response ( $n=6$ neurons, separate sample from Fig. $2 B$; different symbols represent different neurons). Multiple symbols represent different trials. Black line indicates linear regression. B, Superimposed intracellular records (color-coded for clarity) of AE neuron activity in response to electrical pulses (artifact indicated by arrowheads) applied in vocal midbrain. Top traces, Repetitive electrical stimulation leads to EPSP summation that depends on stimulation frequency/PRR (higher PRR leads to larger amplitudes as indicated by the difference in membrane potential dV). Bottom traces, Number of electrical pulses applied to vocal midbrain areas (2 vs 3 ) also leads to differential increases in membrane potential resulting in increased dV. EPSP summation occurs at frequencies $(<60 \mathrm{~Hz}$ ) below the PRR of midshipman fish vocalizations (Bass and McKibben, 2003). Stimulation frequencies are indicated (color-coded).

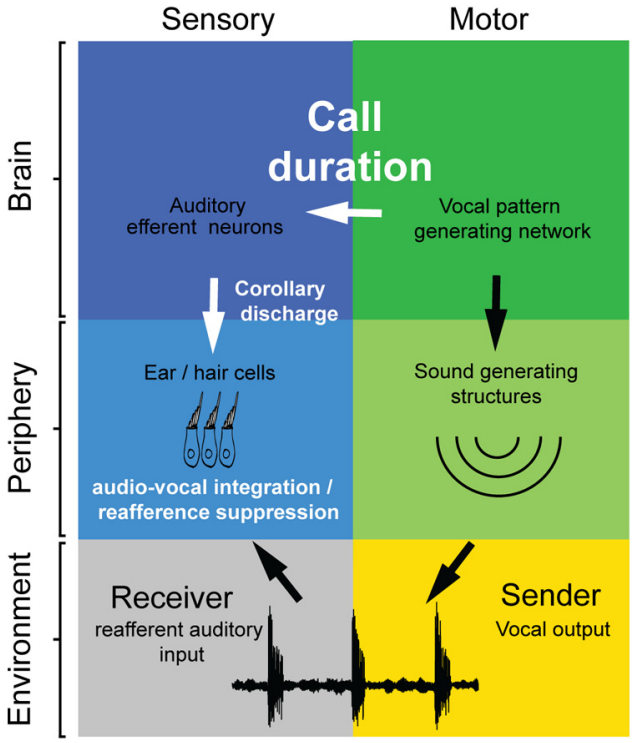

Figure 4. Call duration information from the vocal pattern generator is relayed to the auditory system by AE neurons. AE neurons directly innervate the hair cell epithelium, receive direct input from duration-coding neurons, and generate a VCD. The VCD conveys information about call duration and prevents or diminishes the level of responses to auditory reafference from self-vocalization.

unlike PRR/fundamental frequency, are not determined by the vocal CPG but rather shaped by the vocal organ (Fine et al., 2009; Bradbury and Vehrencamp, 2011) (in this case, the swim bladder), harmonics cannot be conveyed by the VCD. This leaves the VCD unpredictable for a wide range of the frequency spectrum of natural calls. In contrast, duration is set by vocal CPG neurons (VPP, Fig. 1B) (Chagnaud et al., 2011) and is the predominant temporal character transmitted by the VCD of individual AE neurons (Fig. 4).
The above explanation for VCD duration specificity can also apply to sonic tetrapods. For these lineages, the frequency spectrum of calls is dependent on the physical attributes of passively vibrating membranes of the vocal organ (syrinx, larynx) and resonant properties of accessory structures (Bradbury and Vehrencamp, 2011; Herbst et al., 2012). Whereas hindbrain output patterns vocal muscle contraction rate (Bass et al., 2008; Chagnaud et al., 2012), which can influence call frequency by modifying the tension applied to vocal membranes (Bradbury and Vehrencamp, 2011), PRR/fundamental frequency is not directly coded in the brain. The dependency of vocalization on respiratory flow across membranes, together with a wide range of accessory resonant structures, has contributed to a remarkable diversity in the spectral properties of tetrapod vocalizations (Bradbury and Vehrencamp, 2011). For these vertebrates, we see the appearance of vocalrespiratory CPGs in the same neural compartment as the vocal CPG of fishes (Bass et al., 2008) that, as shown here for fishes, are a likely source of VCDs.

We provide evidence that AE neurons are adapted to faithfully transmit VCD duration. A prior study showed that spiking activity in putative $\mathrm{AE}$ axons of the eighth nerve increases in most recordings during fictive vocalizations (Weeg et al., 2005), consistent with our finding of depolarizing potentials in central recordings from AE neurons. These hindbrain neurons, like their olivocochlear homologs (Köppl, 2011), are activated by a variety of sensory stimuli (Highstein and Baker, 1985; Tricas and Highstein, 1990; Delano et al., 2007; Köppl, 2011). Hence, their dendritic arbor requires integration of neuronal inputs from multiple sources, including the vocal activity shown in our results. In contrast, the integration of synaptic inputs in AE neurons does not support the transmission of PRR/fundamental frequency information. Repetitive input to AE neurons led to EPSP summation until firing threshold was reached, at which point neurons no longer fol- 
lowed the input frequency (Fig. 3B). Consequently, AE neurons that showed small oscillations correlated with PRR likely were not able to convey PRR information once the summation of EPSPs reached action potential threshold. This is consistent with a prior study of putative AE axons showing that they do not have spike rates comparable with vocal PRR/fundamental frequency (Weeg et al., 2005). The intrinsic properties of AE neurons apparently make them well adapted for the transmission of duration information but not PRR.

Auditory efferent inputs result in a hyperpolarization of the membrane potential of hair cells in fish (Furukawa, 1981), reptiles (Art et al., 1985), and mammals (Glowatzki and Fuchs, 2000). The time course of this inhibition exceeds the interpulse interval of the PRR/fundamental frequency of midshipman vocalizations (Furukawa, 1981; for toadfish vestibular system, see also Boyle et al., 2009). Thus, even if present, PRR/fundamental frequency information would ultimately be transformed at the hair cell level into a duration signal.

\section{Comparisons with insects and mammals}

The available comparative evidence supports the hypothesis that central and peripheral mechanisms that reduce responses to vocal reafferent signaling share a dependency on call duration. Crickets have corollary discharge interneurons that inhibit auditory afferent input onto central auditory neurons during song (Poulet and Hedwig, 2006, 2007). The duration of inhibition is matched to call duration, with auditory sensitivity restored immediately after self-vocalization. Given the known role of AE neurons in the inhibition of auditory hair cell responses (see above), a similar time course of inhibition that parallels call duration should be expected.

Although the neural circuitry and synaptic basis for a VCD remain to be delineated in mammals, several studies suggest that duration is the predominant temporal character transmitted by a VCD. In monkeys, extracellular recordings in the hindbrain show audio-vocal interactions just before and during self-vocalization (Hage and Jürgens, 2006; Hage et al., 2007). Evoked potential recordings in bats indicate auditory suppression in the hindbrain during self-vocalization (echolocation) (Suga and Schlegel, 1972; Suga and Shimozawa, 1974); the duration of suppression is similar to the duration of natural calls (Wund, 2006). Cochlear microphonic recordings in bats additionally show suppression of activity via hindbrain inputs from the medial olivo-cochlear bundle just before, during, and immediately after self-vocalization (Goldberg and Henson, 1998). Additional projections in midshipman from duration-coding premotor neurons (VPP, Fig. $1 B$ ) to the ascending auditory system (Fig. 1B) (Chagnaud et al., 2011) likely leads to central reafferent suppression as suggested in bats, further emphasizing the importance of call duration in audio-vocal reafference suppression.

In conclusion, the new findings presented here for fish together with the available evidence for mammals would indicate that vertebrates, like insects, have evolved a sonic/VCD carrying call duration information, a salient behavioral cue in both taxa.

\section{References}

Art JJ, Crawford AC, Fettiplace R, Fuchs PA (1985) Efferent modulation of hair cell tuning in the cochlea of the turtle. J Physiol 360:397-421. Medline

Bass AH, Baker R (1990) Sexual dimorphisms in the vocal control system of a teleost fish: morphology of physiologically identified neurons. J Neurobiol 21:1155-1168. CrossRef Medline
Bass AH, McKibben JR (2003) Neural mechanisms and behaviors for acoustic communication in teleost fish. Prog Neurobiol 69:1-26. CrossRef Medline

Bass AH, Marchaterre MA, Baker R (1994) Vocal-acoustic pathways in a teleost fish. J Neurosci 14:4025-4039. Medline

Bass AH, Gilland EH, Baker R (2008) Evolutionary origins for social vocalization in a vertebrate hindbrain-spinal compartment. Science 321:417421. CrossRef Medline

Boyle R, Rabbitt RD, Highstein SM (2009) Efferent control of hair cell and afferent responses in the semicircular canals. J Neurophysiol 102:15131525. CrossRef Medline

Bradbury J, Vehrencamp S (2011) Principles of animal communication. Sunderland, MA: Sinauer.

Chagnaud BP, Baker R, Bass AH (2011) Vocalization frequency and duration are coded in separate hindbrain nuclei. Nat Commun 2: 346:1-11. CrossRef Medline

Chagnaud BP, Zee MC, Baker R, Bass AH (2012) Innovations in motoneuron synchrony drive rapid temporal modulations in vertebrate acoustic signaling. J Neurophysiol 107:3528-3542. CrossRef Medline

Cheung SW, Nagarajan SS, Schreiner CE, Bedenbaugh PH, Wong A (2005) Plasticity in primary auditory cortex of monkeys with altered vocal production. J Neurosci 25:2490-2503. CrossRef Medline

Crapse TB, Sommer MA (2008) Corollary discharge across the animal kingdom. Nat Rev Neurosci 9:587-600. CrossRef Medline

Delano PH, Elgueda D, Hamame CM, Robles L (2007) Selective attention to visual stimuli reduces cochlear sensitivity in chinchillas. J Neurosci 27: 4146-4153. CrossRef Medline

Eliades SJ, Wang X (2008) Neural substrates of vocalization feedback monitoring in primate auditory cortex. Nature 453:1102-1106. CrossRef Medline

Fine ML, King CB, Cameron TM (2009) Acoustical properties of the swimbladder in the oyster toadfish Opsanus tau. J Exp Biol 212:3542-3552. CrossRef Medline

Ford JM, Roach BJ, Mathalon DH (2010) Assessing corollary discharge in humans using noninvasive neurophysiological methods. Nat Protoc 5:1160-1168. CrossRef Medline

Furukawa T (1981) Effects of efferent stimulation on the saccule of goldfish. J Physiol 315:203-215. Medline

Glowatzki E, Fuchs PA (2000) Cholinergic synaptic inhibition of inner hair cells in the neonatal mammalian cochlea. Science 288:2366-2368. CrossRef Medline

Goldberg RL, Henson OW Jr (1998) Changes in cochlear mechanics during vocalization: evidence for a phasic medial efferent effect. Hearing Res 122:71-81. CrossRef Medline

Goodson JL, Bass AH (2002) Vocal-acoustic circuitry and descending vocal pathways in teleost fish: convergence with terrestrial vertebrates reveals conserved traits. J Comp Neurol 448:298-322. CrossRef Medline

Hage SR, Jürgens U (2006) Localization of a vocal pattern generator in the pontine brainstem of the squirrel monkey. Eur J Neurosci 23:840-844. CrossRef Medline

Hage SR, Jürgens U, Ehret G (2007) The olivocochlear system takes part in audio-vocal interaction. In: Hearing: from sensory processing to perception (Kollmeier B, Klump G, Hohmann V, Langemann U, Mauermann M, Uppenkamp S, Verhey J, eds). New York: Springer.

Herbst CT, Stoeger AS, Frey R, Lohscheller J, Titze IR, Gumpenberger M, Fitch WT (2012) How low can you go? Physical production mechanism of elephant infrasonic vocalizations. Science 337:595-599. CrossRef Medline

Highstein SM, Baker R (1985) Action of the efferent vestibular system on primary afferents in the toadfish, Opsanus tau. J Neurophysiol 54:370384. Medline

Highstein SM, Baker R (1986) Organization of the efferent, vestibular nuclei and nerves of the toadfish, Opsanus tau. J Comp Neurol 243:309-325. CrossRef Medline

Kittelberger JM, Bass AH (2013) Vocal-motor and auditory connectivity of the midbrain periaqueductal gray in a teleost fish. J Comp Neurol 521: 791-812. CrossRef Medline

Köppl C (2011) Evolution of the octavolateral efferent system. In: Springer handbook of auditory research: auditory and vestibular efferents (Ryugo DK, Fay RR, Popper AN, eds), pp 217-259. New York: Springer.

Poulet JF, Hedwig B (2006) The cellular basis of a corollary discharge. Science 311:518-522. CrossRef Medline 
Poulet JF, Hedwig B (2007) New insights into corollary discharges mediated by identified neural pathways. Trends Neurosci 30:14-21. CrossRef Medline

Roberts B, Meredith G (1992) The efferent innervation of the ear: variations on an enigma. In: The evolutionary biology of hearing (Webster D, Fay R, Popper A, eds), pp 185-210. New York: Springer.

Rohmann KN, Fergus DJ, Bass AH (2013) Plasticity in ion channel expression underlies variation in hearing during reproductive cycles. Curr Biol 23:678-683. CrossRef Medline

Rubow TK, Bass AH (2009) Reproductive and diurnal rhythms regulate vocal motor plasticity in a teleost fish. J Exp Biol 212:3252-3262. CrossRef Medline

Suga N, Schlegel P (1972) Neural attenuation of responses to emitted sounds in echolocating bats. Science 177:82-84. CrossRef Medline
Suga N, Shimozawa T (1974) Site of neural attenuation of responses to selfvocalized sound sin echolocating bats. Science 183:1211-1213. CrossRef Medline

Tricas TC, Highstein SM (1990) Visually mediated inhibition of lateral line primary afferent activity by the octavolateralis efferent system during predation in the free-swimming toadfish, Opsanus tau. Exp Brain Res 83:233-236. CrossRef Medline

Weeg MS, Land BR, Bass AH (2005) Vocal pathways modulate efferent neurons to the inner ear and lateral line. J Neurosci 25:5967-5974. CrossRef Medline

Wund MA (2006) Variation in the echolocation calls of little brown bats (Myotis lucifugus) in response to different habitats. Am Midl Nat 156:99108. 